\title{
Effects of biofertilizer and manure application on growth rate and chlorophyll content of spinach (Amaranthus tricolor L.) under salinity stress condition
}

\author{
Dwi Umi Siswanti ${ }^{1}$ and Okky Shavira Riesty ${ }^{2}$ \\ ${ }^{1}$ Laboratory of Plant Physiology, Faculty of Biology, Universitas Gadjah Mada, Jl. Teknika Selatan, \\ Sekip Utara Bulaksumur 55281, D.I. Yogyakarta, Indonesia \\ ${ }^{2}$ Department of Biology, Faculty of Biology, Universitas Gadjah Mada, Jl. Teknika Selatan, Sekip \\ Utara Bulaksumur 55281, D.I. Yogyakarta, Indonesia
}

\begin{abstract}
Amaranthus tricolor L. is a widely consumed and cultivated vegetable in Indonesia. Meanwhile, one of the agriculturally usable areas in the country is coastal land. However, the salinity in this land needs to be considered for proper plant growth, therefore, biofertilizer solutions are applied to enhance the growth of plants under salinity stress. This fertilizer is made from livestock urine and microbial strains. In this study, the biofertilizer was applied at a dose of $0,10,20$, and 30 liters/ha while the stress treatment was carried out with $\mathrm{NaCl}$ at a concentration of $0,2,500$ $5,000,7,500$, and $10,000 \mathrm{ppm}$. In addition, manure was also given as a basic fertilizer. The highest growth rate observed in the form of increase in plant height and number of leaves was found in the biofertilizer treatment of 30 and 0 liters/ha. Meanwhile, the highest mean total chlorophyll content was found in plants treated with a dose of 30 liters/ha. Based on the results, it was concluded that the application of biofertilizer affects the growth rate and chlorophyll content of spinach, but only at a certain concentration of salinity levels.
\end{abstract}

\section{Introduction}

Spinach (Amaranthus tricolor L.) is one of the most common vegetable plants in Indonesia and belongs to the Amaranthaceae Family. It is widely consumed due to its high nutritional content. Some of the nutrients contained in this plant include flavonoids, lutein and indole compounds, as well as various vitamins such as A, B, and $\mathrm{K}$. In addition, it also contains other components such as calcium, iron, and phosphorus [7]. These compounds and vitamins perform respective roles and functions in the body, for example, flavonoid contents in spinach act as antioxidants and anticancer.

Indonesia has quite a large coastal area due to its long coastline, therefore, some Indonesian use coastal land for planting. However, the implementation of planting on coastal lands needs to be considered due to the high level of salinity in this area. A high level of salinity inhibits growth and interferes with the productivity of plants. This is overcome by giving special treatment such as fertilizers to enhance growth and prevent inhibition. 
Furthermore, the application of fertilizer to plants plays a role in maintaining growth rate even under stressful conditions.

There are several types of fertilizers with different compositions, the most widely used are compost, manure and NPK fertilizer. Aside from these varieties, biofertilizers are also used to enhance plant growth. It is a biological fertilizer made from livestock urine and contains microorganisms which carry out biological processes. Therefore, biofertilizers increase soil fertility and also produce antibiotics for plants caused by the interaction between microorganisms in the biofertilizer and the rhizosphere [2]. Some of the microorganisms contained in the biofertilizer include Acetobacter sp., Azospirillum sp., Bacillus sp., Cellulomonas sp., Lactobacillus sp., Pseudomonas sp., Rhizobium sp., and Saccharomyces sp. [4].

Chlorophyll is a green pigment contained in plants, particularly in the chloroplasts of the leaves [1]. This pigment plays a role in the photosynthetic process to form a product used as energy for growth and other processes in the plant. Meanwhile, chlorophyll levels vary in different plant depending on several internal and external factors, hence, each plant has respective photosynthetic ability.

Further studies are needed on the effect of biofertilizers on plant growth rates, especially on height, numbers of leaves, and chlorophyll content in plants that grow under salinity stress. Therefore, this study aims to determine the effect of biofertilizer and manure application as basic fertilizer on the growth rate of spinach (Amaranthus tricolor L.) as well as the chlorophyll content in leaves under salinity stress condition.

\section{$2 \quad$ Materials and Methods}

\subsection{Materials and Tools}

The materials used in this study include red spinach seed (Amaranthus tricolor L.), manure, soil as growing media, roasted husks, biofertilizer, polybags, label paper, $\mathrm{NaCl}$, acetone solution $80 \%$, and filter paper. Meanwhile, the tools used are buckets, shovels, zip-lock plastic, plant sprinklers, environmental parameters measuring instruments, ruler, test tubes, mortar, and spectrophotometer.

\subsection{Location and Time}

The spinach was planted at the Faculty of Biology Green House, while the chlorophyll content was measured at the Plant Physiology Laboratory, Faculty of Biology, Gadjah Mada University Yogyakarta from August to October 2020.

\subsection{Methods}

\subsubsection{Planting of Amaranthus tricolor L.}

Amaranthus tricolor L. seeds were initially soaked in warm water for 30 minutes and then planted in polybags containing 5 planting media per bag with uniform spacing. The planting medium used in this study was a mixture of soil : husk : manure in ratio 1:1:1. Plants care was carried out every day with regular watering in the morning and monitoring of pests or other unwanted plants that might interfere with growth. 


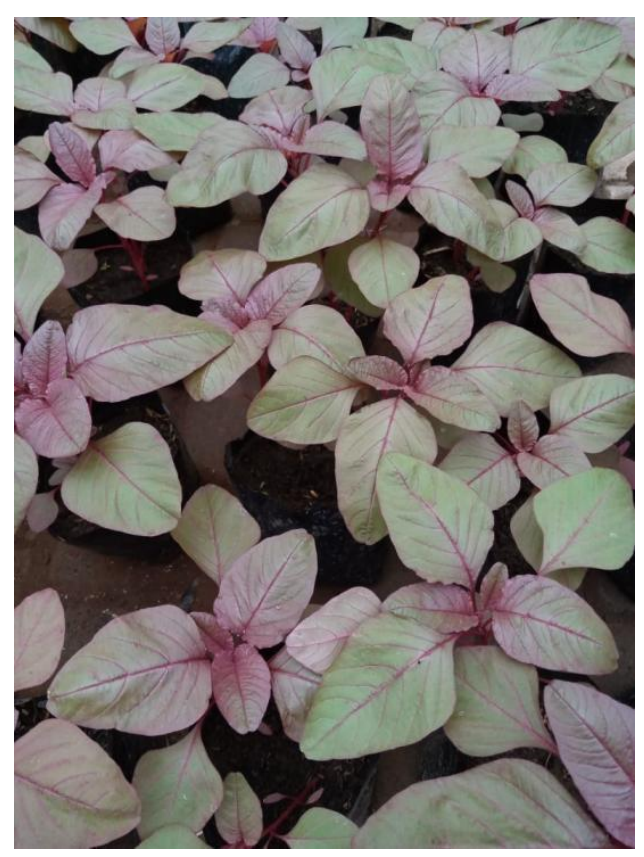

Fig. 1. Amaranthus tricolor L. plant on polybag.

\subsubsection{Treatment}

Two treatments were given to the Amaranthus tricolor L. plants in this study. The first treatment was the application of biofertilizer given after the plants were two weeks old. It was applied by spraying on the surface of the soil at doses of 0 (B0), 10 (B1), 20 (B2), and 30 liters/ha (B3). The biofertilizer doses applied in this study are based on a previous study conducted by Siswanti and Rachmawati (2013), which demonstrated that the application of biofertilizer at a dose of 10 liters/ha produced optimum results on the growth of rice plants (Oryza sativa L.). The treatment was given every 5 days in the afternoon.

The second treatment was the application of $\mathrm{NaCl}$ solution as salinity stress. It was given to plants on the 7th and 14th day after two weeks of seedling by spraying on the soil surface. Meanwhile, the $\mathrm{NaCl}$ was initially diluted into various concentrations, namely 0 (A0) as the control, as well as 2,500 (A1), 5,000 (A2), 7,500 (A3), and 10,000 ppm (A4).

\subsubsection{Measurement of Plant Growth Rate}

The growth rates measured include increase in plant height and the number of leaves. After two weeks of acclimatization, plant height and the number of leaves were measured 2 times a week for a total of 5 measurements. Plant height was measured with a long ruler, while the number of leaves was counted manually. Furthermore, quantitative observations were made in the form of numbers and then entered into the table for further processing, while the growth rate was measured using Microsoft Excel. The growth parameters were measured simultaneously with environmental parameters such as temperature, soil moisture, $\mathrm{pH}$, and light intensity. 


\subsubsection{Measurement of Chlorophyll Content on Leaves}

Leaf samples from each treatment plant were collected at the harvest period to determine the chlorophyll content. One gram of fresh leaf samples was taken and then crushed with a mortar until completely smooth. Furthermore, $80 \%$ acetone was added to the smooth leaves and stirred until homogeneous. The mixture was filtered in a test tube with filter paper and the absorbance value was then determined with a spectrophotometer at 645 and $663 \mathrm{~nm}$ wavelengths. The absorbance value obtained was then entered into the following formula.

Chlorophyll $a=(12.7 \times$ D663 $-2.69 \times$ D645)

(1)

Chlorophyll $b=(22.9 \times D 645-4.68 \times D 663)$

(2)

Total Chlorophyll $=(20.2 \times D 645+8.02 \times$ D663 $)$

(3)

\section{$3 \quad$ Results and Discussions}

Based on the measurements of plant height, number of leaves, and chlorophyll content with a spectrophotometer, the data obtained are shown in Figure 2, 3, and Table 1.

\subsection{Plant Growth Rate}

The growth rate refers to an increase in size or mass, it is influenced by similar factors that affect the plant growth. These factors are divided into internal and external. Internal factors are from within the plant and affect cellular processes, examples include genetic properties and hormones. Meanwhile, external factors are environmental properties that interact directly with plants. Examples of external factors are as follows (1) sunlight which is important for growth and is the most needed factor in the photosynthesis process, (2) water which affects plant growth significantly because it is needed especially by the roots and leaves for photosynthesis and other metabolic processes in plant cells [6].

Furthermore, certain environmental factors inhibit plant growth rates. Environmental stress is a condition of the habitat that is incompatible with the tolerance capacity as well as productivity, and other physiological processes that occur in plants. The occurrence of environmental stress leads to changes in the physiology, morphology, and anatomy of plants.

The rate of increase in plant height forms a sigmoid curve as demonstrated in Figure 2. Based on the results, the application of biofertilizer affected the growth rate of spinach plants, especially the plant height. In the treatment with $0 \mathrm{ppm}$ salinity stress, the highest increase in plant height was found in plants treated with biofertilizers at a concentration of 30 liters/ha. This increase continued in the second observation but decreased on the third and increased again on the fourth observation (Figure 2, A). Similar results were also found in the salinity treatment plot of 5,000 ppm, and biofertilizer concentration of 30 liters/ha. However, the increase in plant height showed an elevated curve in the second observation and then decreased in the third and fourth observations (Figure 2, C). Meanwhile, in the salinity treatment of 2,500,7,500, and 10,000 ppm, the highest plant height increase was observed in plants treated with biofertilizer at a dose of 0 liter/ha with the graphs showing a large increase in plant height at the second observation and a decrease in the third (Figure 2, B; C; D). Based on the results obtained from all salinity concentration treatments, the application of biofertilizer increased the rate of leaf growth in Amaranthus tricolor L. compared to the control. 


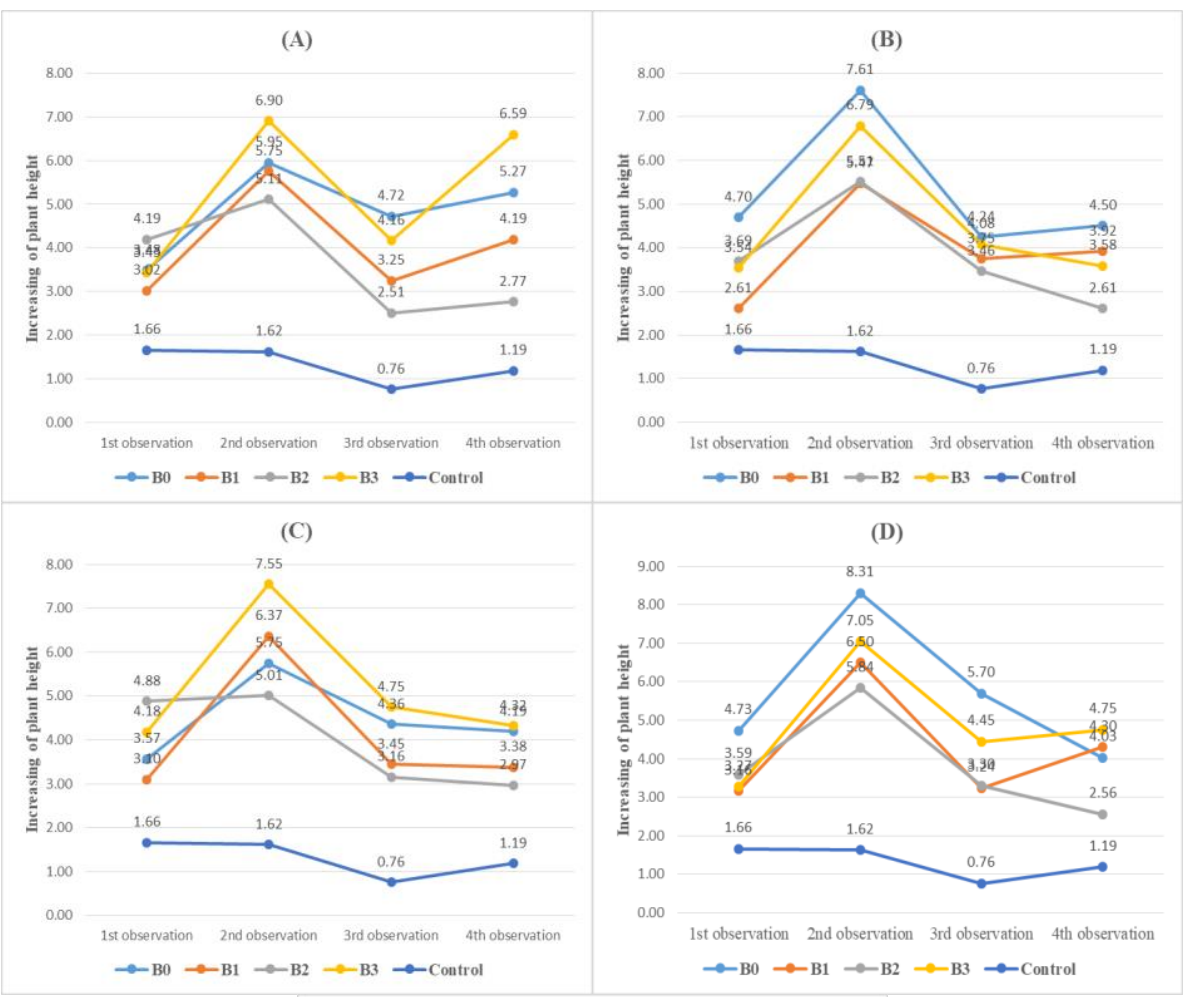

(E)

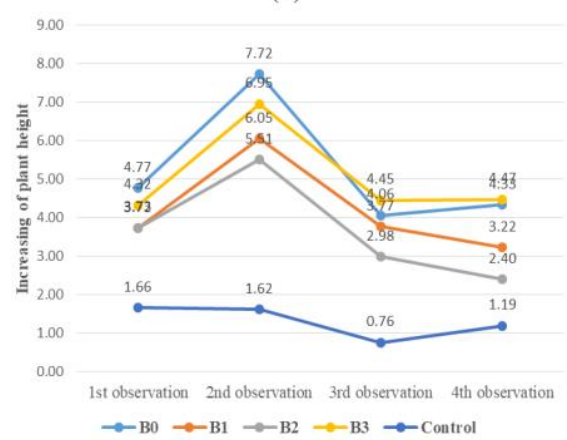

Fig. 2. Rate of increase in Amaranthus tricolor L. plant height with salinity stress condition (A) 0 ppm salinity level, (B) 2,500 ppm salinity level, (C) 5,000 ppm salinity level, (D) 7,500 ppm salinity level, (E) 10,000 ppm salinity level, 'control' are plants without salinity stress and biofertilizer treatment. 


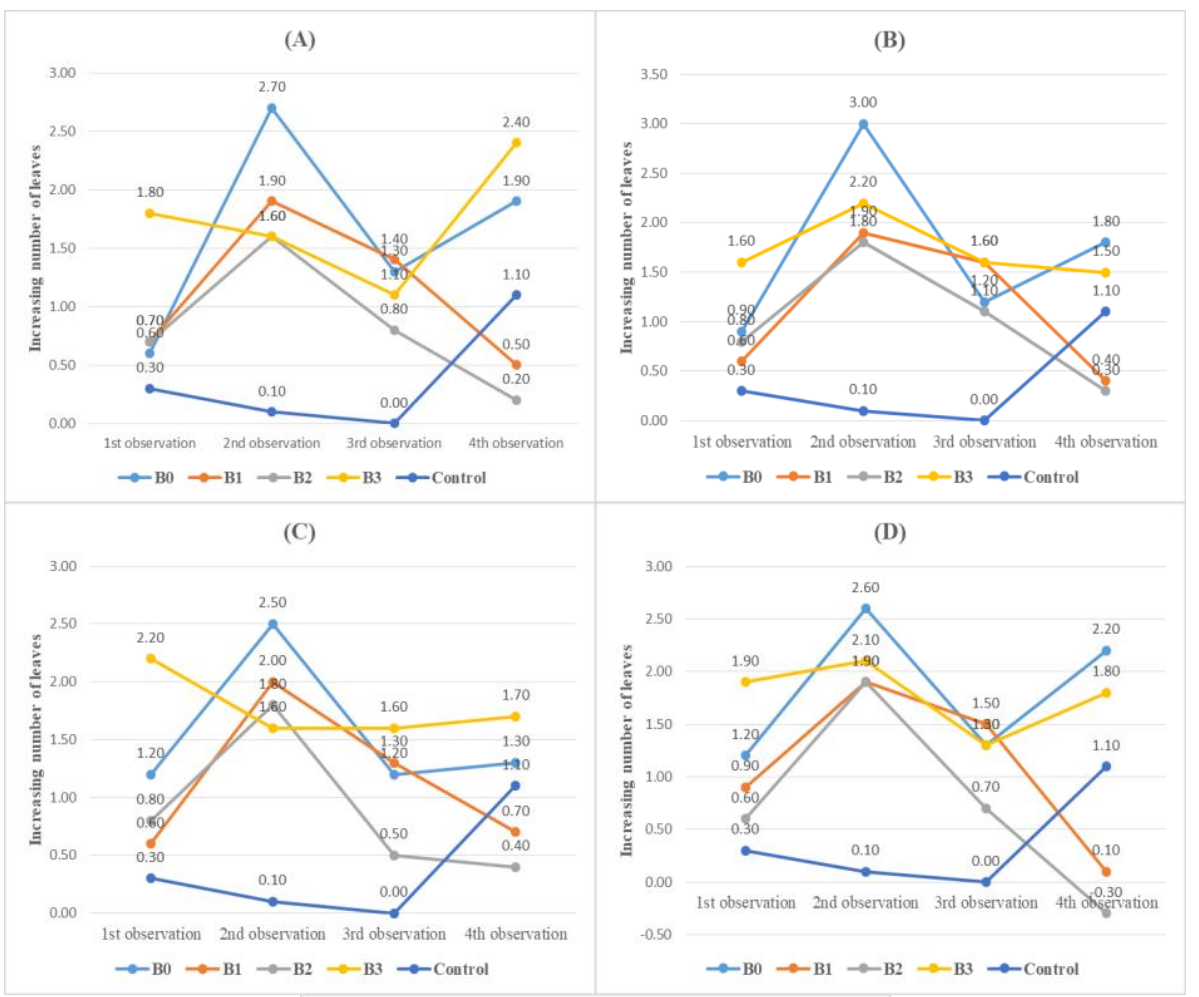

(E)

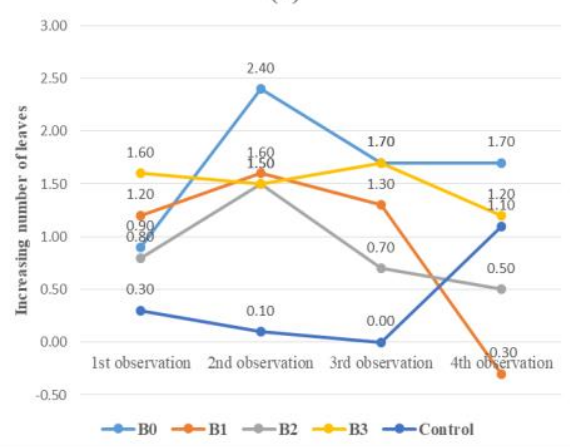

Fig. 3. Rate of increase in Amaranthus tricolor L. number of leaves with salinity stress condition (A) 0 ppm salinity level, (B) 2,500 ppm salinity level, (C) 5,000 ppm salinity level, (D) 7,500 ppm salinity level, (E) 10,000 ppm salinity level, 'control' are plants without salinity stress and biofertilizer treatment.

To measure the number of leaves in the plant, a graph was made to show the rate of increase calculated based on the differences between the numbers. The highest rate of leaf growth was shown in plants given biofertilizer at a dose of 0 liters/ha (control). The plant growth rate in this treatment increased in the second observation, decreased in the third, and then increased again in the fourth observation (Figure 3, A; B; C; D). These results suggest that the application of biofertilizer to plants increased the number of leaves even under various concentrations of salinity stress. This is demonstrated in the differences between the linear graphs of the treatment and control plants.

The plants in the treatment group showed higher increase in plant height for several observations. However, the control plants had a lower and declining growth rate. The 
treatment plants had a high rate because the stress condition was moderate, hence, the plants continued to grow until the end of the observation. Therefore, the salinity stress in the form of $\mathrm{NaCl}$ did not affect Amaranthus tricolor L. planted in this study. Furthermore, aside the treatments namely salinity stress at various concentrations and biofertilizer, the plants were also treated with manure as basic fertilizer. The application of manure and biofertilizer is presumably responsible for the continued growth observed in the plants despite the various level of salinity. A similar result was also found in pakchoi plants where the application of biofertilizer composed of weed, cow dung, and harvest residues influenced plant growth [9].

The application of biofertilizer increased the growth rate of plants as indicated in the graph of plant height in all treatments. Similar results were also shown in the rate of increase in the number of leaves. The control plants had a lower rate compared to the treatment plants. In all treatments, an increase in the number of leaves was observed in the second observation, namely after biofertilizer treatment. This shows that the application of biofertilizer increased the growth rate of plants due to the presence of several microbes which trap nutrients and also degrade organic matter in the soil [8].

The application of biofertilizer in rice plants (Oryza sativa L.) at a dose of 10 liters/ha increased growth as well as the nutrient content in the soil [5]. In the spinach plants observed in this study, the biofertilizer dose with the highest growth rate was 30 liters/ha (B3). Therefore, the spinach plant requires a larger dose of biofertilizer than rice. The difference in biofertilizer requirements of spinach and rice plants occur due to several factors, including plant physiology, as each plant has respective needs for nutrients. Furthermore, biofertilizer with a dose less than 30 liters/ha produced a lower growth rate. However, the results showed that the growth rate in the B0 treatment was also high. This is probably caused by the effect of other factors that influence the growth rate of spinach in this treatment. One of the most likely factors in this study is light, meanwhile, environmental parameters such as light intensity, temperature, and soil moisture are measured simultaneously with growth rate. At each measurement, the $\mathrm{B} 0$ plant plots have the highest light intensity value compared to the other biofertilizer treatment plots. Besides, light is one of the main factors that influence plant growth. Although the B0 plants were not given biofertilizer, the plants in this treatment received the highest sunlight intensity compared to other treatments. Therefore, these plants continue to grow as indicated by the high growth rate. In addition, the planting media were added with manure as basic fertilizer which also enhanced the growth of plants. Manure increases the concentration of nitrogen, calcium, magnesium, and phosphorus in the soil. The animal used as the manure source also affects its effectiveness in enhancing plant growth, this includes chicken, cow, and quail manure. Putra et al. showed that quail manure produced the best results in increasing root length and surface area, as well as leaf area of curly red chili plants $[11,12]$. The biofertilizer dose applied in this study was not sufficient for the nutritional needs of the spinach plant, therefore, it had no significant effect on the growth rate.

\subsection{Chlorophyll Content of Plant Leaves}

The chlorophyll content in the leaves was determined by calculating the absorbance value with a spectrophotometer at 645 and $663 \mathrm{~nm}$ wavelengths. Based on the results, the values of chlorophyll a, chlorophyll b, and total chlorophyll in Amaranthus tricolor L. are presented in Table 1 . 
Table 1. Chlorophyll content on Amarantus tricolor L..

\begin{tabular}{cccc}
\hline \multirow{2}{*}{ Treatment } & \multicolumn{2}{c}{ Leaf Chlorophyll Content } \\
\cline { 2 - 4 } & Chlorophyll-a & Chlorophyll-b & $\begin{array}{c}\text { Total } \\
\text { Chlorophyll }\end{array}$ \\
\hline Control & $2.68^{\mathrm{b}}$ & $2.27^{\mathrm{b}}$ & $4.95^{\mathrm{b}}$ \\
\hline A0B0 & $6.33^{\mathrm{a}}$ & $3.85^{\mathrm{ab}}$ & $10.18^{\mathrm{a}}$ \\
\hline A1B0 & $5.6^{\mathrm{a}}$ & $3.3^{\mathrm{ab}}$ & $8.9^{\mathrm{ab}}$ \\
\hline A2B0 & $6.74^{\mathrm{a}}$ & $4.02^{\mathrm{ab}}$ & $10.75^{\mathrm{a}}$ \\
\hline A3B0 & $4.79^{\mathrm{ab}}$ & $2.78^{\mathrm{ab}}$ & $7.57^{\mathrm{ab}}$ \\
\hline A4B0 & $5.59^{\mathrm{a}}$ & $3.47^{\mathrm{ab}}$ & $9.06^{\mathrm{ab}}$ \\
\hline A0B1 & $5.72^{\mathrm{a}}$ & $3.43^{\mathrm{ab}}$ & $9.14^{\mathrm{ab}}$ \\
\hline A1B1 & $6.2^{\mathrm{a}}$ & $3.66^{\mathrm{ab}}$ & $9.85^{\mathrm{a}}$ \\
\hline A2B1 & $5.87^{\mathrm{a}}$ & $3.51^{\mathrm{ab}}$ & $9.38^{\mathrm{a}}$ \\
\hline A3B1 & $6.01^{\mathrm{a}}$ & $3.54^{\mathrm{ab}}$ & $9.55^{\mathrm{a}}$ \\
\hline A4B1 & $6.12^{\mathrm{a}}$ & $3.7^{\mathrm{ab}}$ & $9.81^{\mathrm{a}}$ \\
\hline A0B2 & $5.51^{\mathrm{a}}$ & $3.26^{\mathrm{ab}}$ & $8.76^{\mathrm{ab}}$ \\
\hline A1B2 & $5.79^{\mathrm{a}}$ & $3.27^{\mathrm{ab}}$ & $9.06^{\mathrm{ab}}$ \\
\hline A2B2 & $7.07^{\mathrm{a}}$ & $4.16^{\mathrm{ab}}$ & $11.23^{\mathrm{a}}$ \\
\hline A3B2 & $6.99^{\mathrm{a}}$ & $4.16^{\mathrm{ab}}$ & $11.15^{\mathrm{a}}$ \\
\hline A4B2 & $7.17^{\mathrm{a}}$ & $4.6^{\mathrm{a}}$ & $11.77^{\mathrm{a}}$ \\
\hline A0B3 & $7.39^{\mathrm{a}}$ & $4.53^{\mathrm{a}}$ & $11.91^{\mathrm{a}}$ \\
\hline A1B3 & $6.26^{\mathrm{a}}$ & $3.56^{\mathrm{ab}}$ & $9.81^{\mathrm{a}}$ \\
\hline A2B3 & $5.44^{\mathrm{a}}$ & $3.03^{\mathrm{ab}}$ & $8.46^{\mathrm{ab}}$ \\
\hline A3B3 & $6.4^{\mathrm{a}}$ & $3.85^{\mathrm{ab}}$ & $10.24^{\mathrm{a}}$ \\
\hline A4B3 & $5.58^{\mathrm{a}}$ & $3.27^{\mathrm{ab}}$ & $8.84^{\mathrm{ab}}$ \\
\hline
\end{tabular}

Table 1 shows that the treatment with the highest chlorophyll a and $\mathrm{b}$ content was A0B3 with 7.39, and A4B2 with $4.60 \mathrm{mg} / 1$ respectively, while the highest total chlorophyll content was found in A0B3 with a value of $11.91 \mathrm{mg} / \mathrm{l}$. In contrast, the treatment with the lowest chlorophyll $\mathrm{a}$ and $\mathrm{b}$ content was found in A3B0 with 4.79 and A3B0 with $2.78 \mathrm{mg} / \mathrm{l}$ respectively, while the lowest total chlorophyll content was found in $\mathrm{A} 3 \mathrm{~B} 0$ with a value of $7.57 \mathrm{mg} / \mathrm{l}$. These results show that majority of the plants treated with biofertilizer with doses of 20 and 30 liters/ha (B2 and B3) have high chlorophyll a and b, as well as total chlorophyll. However, there was no observable significant effect in terms of salinity levels. Therefore, the $\mathrm{NaCl}$ treatment given as salinity stress did not significantly affect the amount of chlorophyll content in spinach leaves plants observed in this study. Halim et al. (2019) [3], in a study on the tolerance of red spinach to salinity stress, stated that the plant still had tolerance at a salinity stress level of $8000 \mathrm{ppm}$, supported by the provision of urea, SP-36, and $\mathrm{KCl}$ fertilizers. The spinach plants used in this study have a higher tolerance to salinity stress due to several factors, including genetic characteristics of the seeds or the plant as a whole. It might also be caused by an association between the plant and nitrogen-fixing bacteria or Mycorrhizae in soil which maintains and increases the growth of plants in saline soil conditions [10].

Similar to the use of other fertilizers in agriculture, biofertilizers with the right dose also enhance plant growth rate. In this study, the application of biofertilizer at doses of 20 and 30 liters/ha produced optimal chlorophyll content compared to 0 and 10 liters/ha. Meanwhile, chlorophyll synthesis in plants requires several elements such as nitrogen $(\mathrm{N})$ and phosphorus (P) which are processed through enzymatic reactions and affected by environmental factors such as temperature (Li et al., 2018). Furthermore, soil and temperature are important factors 
that influence the synthesis of chlorophyll in plants. The application of biofertilizer at doses of 20 and 30 liters/ha increased chlorophyll synthesis in addition to environmental factors. This value is higher than the optimal biofertilizer required in rice (Oryza sativa L.).

The data analysis result obtained using the DMRT test with SPSS software showed that there was a significant difference in the chlorophyll content of all treatments except A3B0 compared to the control. Furthermore, the chlorophyll b content in the control plants was not significantly different from other treatments except A4B2 and A0B3, while, the total chlorophyll content in the control plants was significantly different in all treatments except A3B0, A4B0, A0B1, A0B1, A0B2, A1B2, A2B3, and A4B3.

\section{Conclusions}

Based on the results, it was concluded that biofertilizer application with manure as basic fertilizer affects the growth rate and chlorophyll content in Amaranthus tricolor L. under salinity stress conditions. Majority of the plants treated with biofertilizer dose of 30 liters/ha produced a higher growth rate and chlorophyll content in leaves compared to other treatments. However, the results obtained especially on plant growth rates are still not effective. Therefore, further studies are needed on the effect of biofertilizer in red spinach under salinity stress conditions to ascertain the optimal dose or the most effective combination of other fertilizers with biofertilizer to increase plant growth rate.

The authors are grateful to Universitas Gadjah Mada for the RTA grant (contract number 2488/UNI.P.III/DIT-LIT/PT/2020) given for this study.

\section{References}

1. A. H. Jackson, Structure, Properties, and Distribution of Chlorophyll, in Chemistry and Biochemistry of Plant Pigments (Academic Press, London, 1976)

2. A. Kartikawati, O. Trisilawati, I. Darwati, Perspektif, 1 (2017)

3. B. Halim, I. Sasli, D. Anggorowati, J Sains Mahasiswa Pertanian Universitas Tanjungpura (2019)

4. D. Sudiarti, J SainHealth, 1, 2 (2017)

5. D. U. Siswanti, D. Rachmawati, Biogenesis 2 (2013)

6. G. Toole G, S. Toole S, AQA Biology: A Level (Oxford University Press, United Kingdom, 2015)

7. H. Sunarjono, F. A. Nurrohmah, Bertanam Sayuran Daun \& Umbi. (Penebar Swadaya, Jakarta. 2018)

8. I. M. A. Habib, D. S. Sukamto, L. Maharani, J Folium, 1, 1 (2017)

9. M. Handajaningsih, U. Siswanto, T. Adiprasetyo, Hidayat, B. Purnomo, Marwanto, L. Nuri, The Suitability of Different Sources of Biofertilizers to Support Sustainability of Organic Vegetables Practice in Bengkulu Province of Indonesia, 10.31227/osf.io/gyjfv (2017)

10. M. Hanin, C. Ebel, L. Ngom, L. Laplaze, K. Masmoudi, Frontiers in Plant Science, 7 (2016)

11. S. H. Han, J. Y. An, J. Hwang, S. B. Kim, B. B. Park, Forest Sci. and Tech., 12, 3 (2016)

12. S. S. Putra, E. T. S. Putra, J. Widada, Caraka Tani: J. of Sustainable Agriculture, 35, 2 (2020) 